\title{
Electrochemical, Structural and Nano Tribological Behavior of Ni-W-PTFE Nanocomposite Coatings Prepared by Tartrate Bath
}

\author{
Amir Farzaneh ${ }^{1}$, Mir Ghasem Hosseini ${ }^{2, *}$, Shahin Khameneh Asl ${ }^{1}$, Omer Mermer ${ }^{3, *}$ \\ ${ }^{1}$ Department of materials engineering, Faculty of Mechanical Engineering, University of Tabriz, \\ Tabriz, Iran, \\ ${ }^{2}$ Department of Physical Chemistry, Electrochemistry Research Laboratory, University of Tabriz, \\ Tabriz, Iran, \\ ${ }^{3}$ Department of Electrical and Electronic Engineering, Ege University, 35100, İzmir, Turkey \\ *E-mail: $\underline{\text { mg-hosseini@ tabrizu.ac.ir, omer.mermer@ege.edu.tr }}$
}

doi: $10.20964 / 2016.06 .86$

Received: 10 March 2016/Accepted: 27 April 2016 / Published: 4 May 2016

\begin{abstract}
A tartrate nickel plating bath has been used to prepare nickel- tungsten (Ni-W) dispersed PTFE composite coatings with four different PTFE contents $\left(0,4,8\right.$ and $\left.20 \mathrm{gl}^{-1}\right)$. The coatings are characterized using of Field-Emission Scanning Electron Microscopy (SEM), Energy Dispersive Xray Analysis (EDAX) and X-ray Diffractrometry (XRD). XRD results indicate that the PTFE particle changed the surface texture significantly. The nano tribological behavior of the nano composite coating was estimated by contact mode of AFM. Electrochemical performance of the nanocomposite depositions was evaluated using potentiodynamic polarization and electrochemical impedance spectroscopy (EIS). The results show that the Ni-W/PTFE nanocomposite films exhibit better electrochemical and tribological performance than the Ni-W coating. The corrosion rate and surface roughness decreased about 50 and 5 times less than bare coating in optimum condition $8 \mathrm{gl}^{-1} \mathrm{PTFE}$.
\end{abstract}

Keywords: Ni-W/PTFE, nanocomposite coatings, tartrate bath, nano-tribological, electrochemical performance.

\section{$\underline{\text { FULL TEXT }}$}

(C) 2016 The Authors. Published by ESG (www.electrochemsci.org). This article is an open access article distributed under the terms and conditions of the Creative Commons Attribution license (http://creativecommons.org/licenses/by/4.0/). 